HIGH SPEED SINGLE CRYSTAL CASTING TECHNIQUE

\author{
Shogo Morimoto, Akira Yoshinari \\ Hitachi Research Lab., Hitachi Ltd. \\ 832 Horiguchi Katsuta, Ibaraki, 312 Japan \\ Eisuke Niyama \\ Tohoku Univ. \\ Aoba Aramaki Sendai, Miyagi, 980 Japan
}

\begin{abstract}
Production of a single crystal with a $<100>$ direction with good yield and at a higher speed is an important factor for improving the productivity in a mold withdrawal unidirectional solidification method. This factor was investigated both in solidification calculations and casting experiments. It was found that casting conditions, such as the pouring temperature and the mold heating temperature, are important in the production of a single crystal with a $<100>$ direction; and by optimizing these conditions, <100> single crystals were produced with good yield. In order to increase the speed of production of a single crystal, attempts were made at providing a high temperature gradient at the solidification front by two stage heating and regulation of convection by a magnetic field. Two stage heating was effective for increasing the temperature gradient solely without raising the temperature of the molten metal as a whole, and facilitated the production of a single crystal airfoil having a complicated shape. On the other hand, the application of a magnetic field had a deleterious effect and produced typical freckles.
\end{abstract}


Single crystal castings of $\mathrm{Ni}$-base superalloys exhibit excellent characteristics at high temperature $(1,2)$. They have begun to be used as buckets or nozzles of jet engines for aircraft, and are expected to be used as buckets and nozzles for heavy duty gas turbines in the near future.

The characteristics such as the high temperature strength and thermal fatigue strength of a single crystal casting of a $\mathrm{Ni}$-base superalloy are excellent when the casting is crystallized in the direction of $\langle 100\rangle(3)$. It is therefore essential for bringing the characteristics of a single crystal into full play to make the direction of the main stress of the airfoil the $\langle 100\rangle$ direction of the crystal.

The direction of crystallization of a single crystal casting is controlled by a seeding method or a selector method. Although it is difficult to directly control the direction of a single crystal by a selector method, it is suitable for industrial production in the respect that it is a comparatively simple manufacturing method. Accordingly, factors for controlling the direction of crystallization by the selector method were investigated by calculation and experiments.

On the other hand, single crystal castings produced by a mold withdrawal unidirectional solidification method are much more expensive than those produced by an ordinary casting method because the solidification time is so long as to lower the productivity. In order to apply a single crystal airfoil to heavy duty gas turbines, improvement of the productivity is therefore essential and development of a solidification controlling technique is required.

One of the factors for improving the productivity is a higher withdrawal rate. For this purpose, attempts were made at providing a high temperature gradient at the solidification front and regulation of convection. As a method of providing a high temperature gradient, a two stage heating process was inyestigated in which the temperature of the bottom of the susceptor was raised $(4)$. This was because it was believed that the two stage heating process would increase the temperature gradient solely without raising the temperature of the molten metal as a whole. As a method of regulating convection, application of a static magnetic field was investigated. This method is called an MCZ method and is adopted for production of a highquality Si single crystal $(5)$. We supposed that if the solidification speed was increased, the solidification front would become unstable and the convection produced was regulated by the magnetic viscosity $(6)$ and, hence, the production of new crystal and the deterioration of crystallinity would be regulated.

The results of these investigations are reported in this paper.

Method for Research

Calculation Method

Solidification calculations were carried out both on a model starter and on a model airfoil having a simplified two-dimensional shape. Fig. 1 shows the calculation model. The calculation model of the airfoil had a two-dimensional plate shape, while the starter had a two-dimensional columnar shape. Calculation was carried out by an explicit finite difference scheme $(7)$. On the assumption that the heat transfer between the mold surface and the atmosphere was of a Newtonian type, an apparent heat transfer coefficient was used. The coefficients used in the calculation are shown in Table 1. Thermo-physical values used in the calculation were assumed to be constant irrespective of the temperature. When the mold withdrawal rate was calculated, the apparent heat transfer coefficient and atmospheric temperature were varied as a function of time and distance from the chillplate. 
Table 1 Physical properties used in the calculation

\begin{tabular}{|c|c|c|c|}
\hline & standard & variation \\
\hline \multicolumn{2}{|l|}{ Density (Metal) } & 8.9 & \\
\hline \multicolumn{2}{|l|}{ Specific heat (Metal) } & 0.11 & \\
\hline \multicolumn{2}{|c|}{ Thermal conductivity (Metal) (cal/cm. $\left.{ }^{\circ} \mathrm{C} . \mathrm{s}\right)$} & 0.07 & \\
\hline \multicolumn{2}{|l|}{ Liquidus } & 1390 & \\
\hline \multicolumn{2}{|l|}{ Solidus } & 1350 & \\
\hline \multicolumn{2}{|l|}{ Latent heat of solidification } & 75 & \\
\hline \multicolumn{2}{|l|}{ Density (Mold) } & 2.4 & \\
\hline \multicolumn{2}{|l|}{ Specific heat (Mold) } & 0.25 & \\
\hline \multicolumn{2}{|c|}{ Thermal conductivity (Mold) $\left(\mathrm{cal} / \mathrm{cm} .{ }^{\circ} \mathrm{C} . \mathrm{s}\right)$} & 0.003 & \\
\hline \multicolumn{2}{|l|}{ Time increment } & 0.03 & \\
\hline $\begin{array}{c}\text { Heat Transfer Coefficient } \\
\text { (cal/cm.s.deg) }\end{array}$ & $\begin{array}{l}\text { Casting-Chill } \\
\text { Mold-Chill } \\
\text { Mold-Susceptor } \\
\text { Chil1-7 cm } \\
7 \mathrm{~cm} 24 \mathrm{~cm} \\
\text { Mold-Atmosphere }\end{array}$ & $\begin{array}{r}0.001 \\
0.0015 \\
0.00075 \\
\end{array}$ & \\
\hline $\begin{array}{r}\begin{array}{r}\text { Susceptor Temperature } \\
\left({ }^{\circ} \mathrm{C}\right)\end{array} \\
\end{array}$ & $\begin{array}{l}\text { Upper Heater } \\
\text { Lower Heater }\end{array}$ & $\begin{array}{l}1500 \\
1600\end{array}$ & $\begin{array}{l}1500-1650 \\
1400-1650\end{array}$ \\
\hline Heater Height $(\mathrm{cm})$ & $\begin{array}{l}\text { Upoer Heater } \\
\text { Lower Heater }\end{array}$ & $\begin{array}{r}17 \\
7 \\
\end{array}$ & $\begin{array}{r}17-24 \\
0-7 \\
\end{array}$ \\
\hline \multicolumn{2}{|l|}{ Chillplate Temperature } & 20 & \\
\hline \multicolumn{2}{|l|}{ Withdrawal Velocity of Moid } & 20 & \\
\hline
\end{tabular}

\section{Casting Experiment}

A single crystal of a $\mathrm{Ni}$-base superalloy was cast by the apparatus shown in Fig. 2 in a vacuum of about $10^{-4}$ Torr. The susceptor in Fig. 2 was divided into two parts so as to control the temperature at the top and at the bottom separately from each other. A magnetic field for convection was applied from the outside of the furnace wall by a DC electromagnet. The magnetic field intensity was $2000 \mathrm{G}$ at maximum at the center of the furnace. Table 2 shows the chemical composition of the alloys used in the experiments. The pouring temperature, the mold heating temperature, the mold withdrawal rate, etc., were varied in the casting experiments. The temperature of the mold was measured by a platinum thermocouple.

In the convection regulation experiments, a test piece of a bar having a $15 \mathrm{~mm}$ diameter was cast. After casting, the mold was withdrawn downwardly for effecting unidirectional solidification while a magnetic field was being applied.

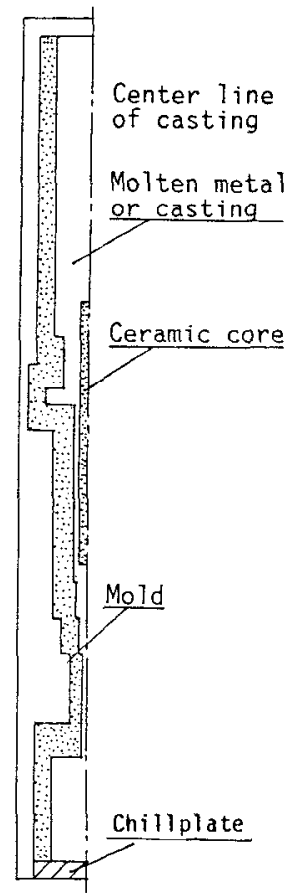

Fig. I Calculation model.

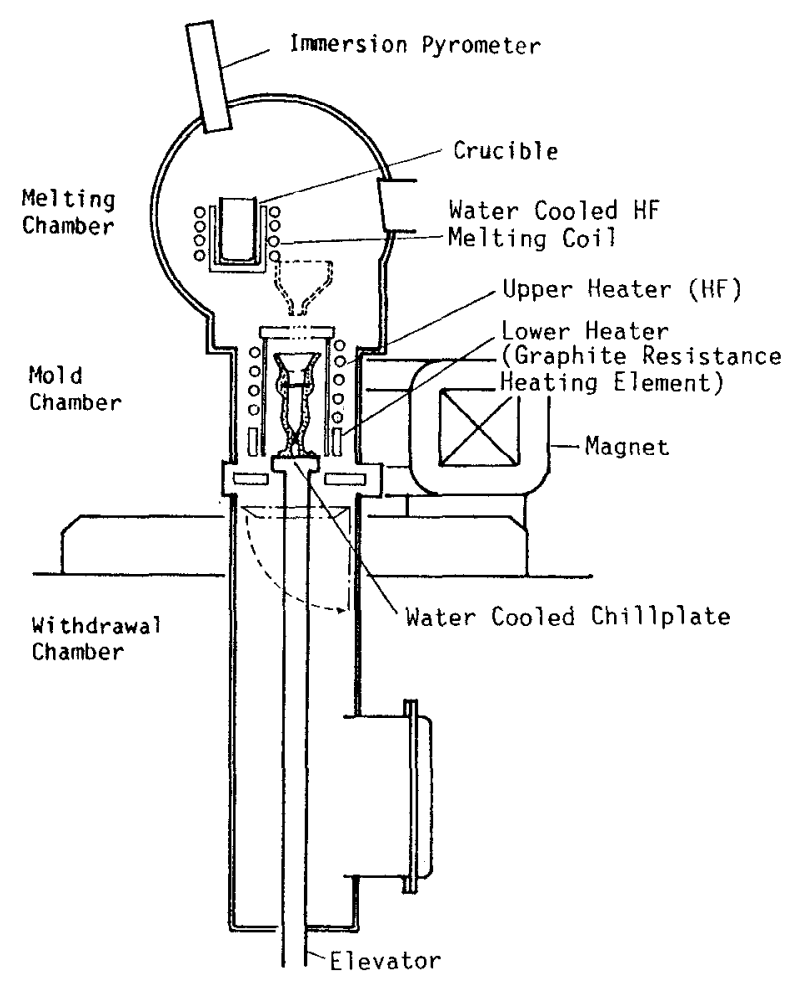

Fig. 2 Schematic structure of single crystal casting furnace. 
Table 2 Chemical composition of S.C. Alloys (w\%)

\begin{tabular}{lrrrrrrrrr}
\hline Alloy & Cr & Mo & \multicolumn{1}{c}{ W } & Co & Ta & Al & Ti & Hf & Ni \\
\hline NASAIR-100 & 9.0 & 1.0 & 10.5 & & 3.2 & 5.7 & 1.2 & & bal \\
CMSX-3 & 8.0 & 0.6 & 8.0 & 4.6 & 6.0 & 5.6 & 1.0 & 0.1 & bal \\
TMS-12 & 6.6 & & 12.8 & & 7.7 & 5.2 & & & \\
TMS-26 & 5.6 & 1.85 & 10.9 & 8.2 & 7.7 & 5.1 & & & bal \\
\hline
\end{tabular}

Results and Discussion

Control of Direction of Growth

Single crystal test pieces were cast under various conditions, and the effects of the shape of the selector and the structure of the starter on the direction of a single crystal were examined. As a result, it was found that the direction of a single crystal has no relation to the shape of the selector and that the structure of the starter is important. More specifically, in order to obtain the $\langle 100\rangle$ direction of a single crystal, it is important to grow a columnar crystal in the starter upward perpendicularly to the chillplate. It was considered that in order to grow a columnar crystal upward perpendicularly to the chillplate the solidification front in the starter must be horizontal, and single crystals were cast while varying the mold heating conditions.

Fig. 3 shows the distribution of the mold temperature. Temperature distribution (1) represents a conventional heating condition and temperature distribution (2) a mold temperature in which the temperature is maintained at 1300 to $1350^{\circ} \mathrm{C}$ below the starter and $1390^{\circ} \mathrm{C}$ above half of the height of the starter on the basis of the results of the calculation.

Fig. 4 shows the results of the calculation for the change of the solidification front (1iquidus) with time when the pouring temperature was varied. The mold heating is the same as temperature distribution (1) shown in Fig. 3. From the results of the calculation, it is not expected that the columnar crystal will grow sufficiently from the chillplate to the portion above the starter (entrance of the selector) because the solidification front protrudes downwardly

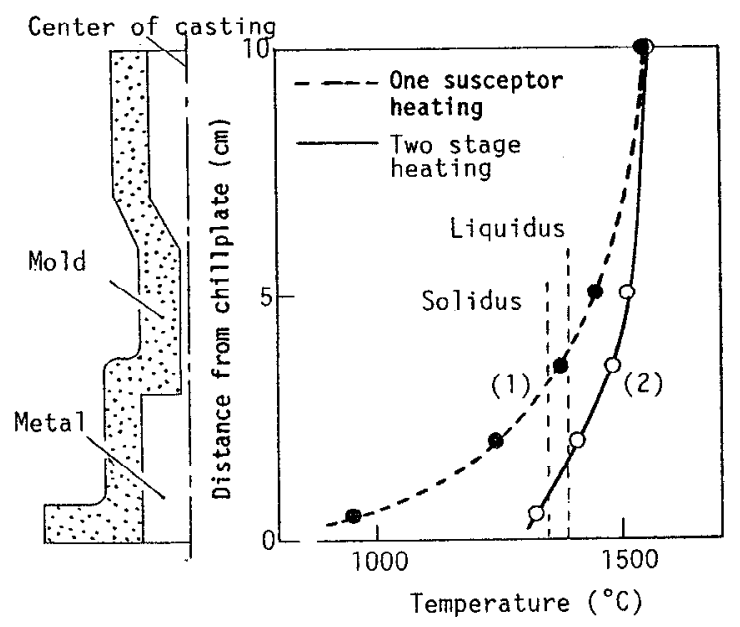

Fig. 3 Temperature profile of mold.

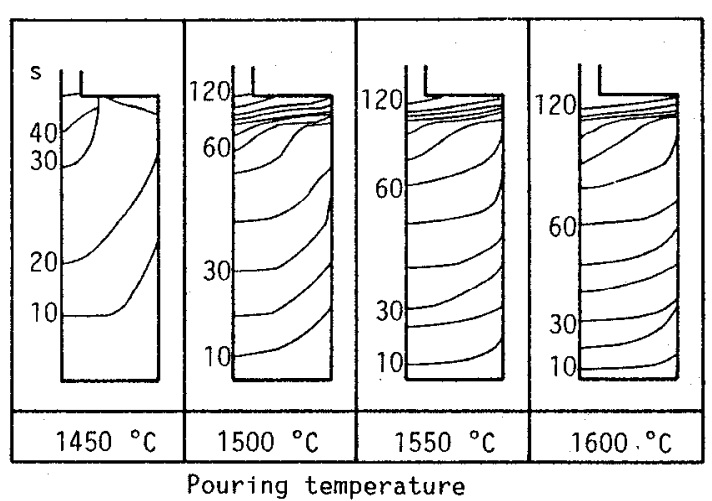

Fig. 4 Effect of pouring temperature on the location of solidification front vs. time elapsed.

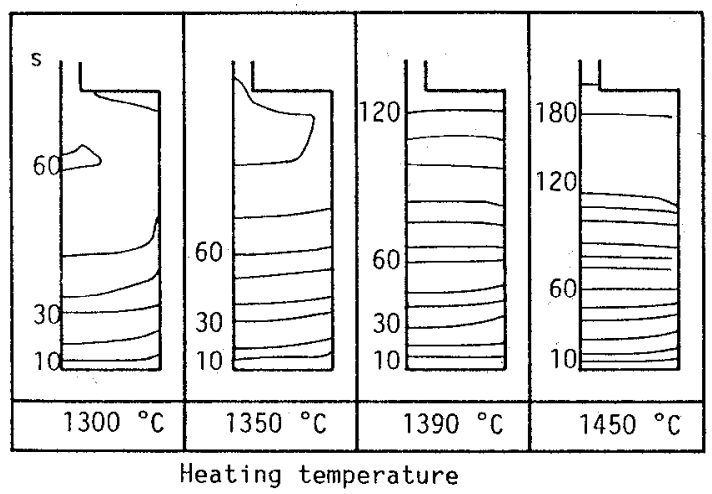

Fig. 5 Effect of mold temperature on the location of solidification front vs. time elapsed. 
to a great extent at a pouring temperature of $1450^{\circ} \mathrm{C}$. When the pouring temperature is $1500^{\circ} \mathrm{C}$, the solidification front in the vicinity of the center line becomes substantially horizontal. If the pouring temperature is raised further, the area of horizontal solidification is enlarged, but the solidification front protrudes downwardly at the outer peripheral portion which is in contact with the mold.

Fig. 5 shows the results of the calculation for the change in the solidification front with time when the mold temperature was varied. The mold heating temperature was constant in the furnace. The solidification front was horizontal at about $1 / 3$ of the height of the starter when the mold heating temperature was $1300^{\circ} \mathrm{C}$, and at about $2 / 3$ of the height of the starter when the mold heating temperature was $1350^{\circ} \mathrm{C}$ (solidus). When the mold heating temperature is higher than $1390^{\circ} \mathrm{C}$ (1 iquidus), the solidification front is horizontal over the entire area of the starter and a columnar crystal is expected to grow upward perpendicular to the chill.

From the above results, it was found that even if the pouring temperature is low, the mold cools the molten metal and it is impossible to obtain a completely horizontal solidification front. Since the raise of the mold heating temperature was considered to be most effective for obtaining a horizontal solidification front, temperature distributions (1) and (2) were investigated by both calculation and by casting experiment.

Fig. 6 shows the results of the calculation of the change in the solidification front with time and the macrostructure of the starter when the mold heating temperature was varied in accordance with Fig. 3 . When the heating temperature is in agreement with temperature profile (1), the solidification front protrudes downwardly due to the chill from the mold. From observations of the macrostructure, it is clear that a large columnar crystal exists at the outer peripheral portion, which in fact corresponds to the results of the calculation. Thus, it was found that the heating condition in accordance with temperature profile (1) cannot produce a horizontal solidification front.

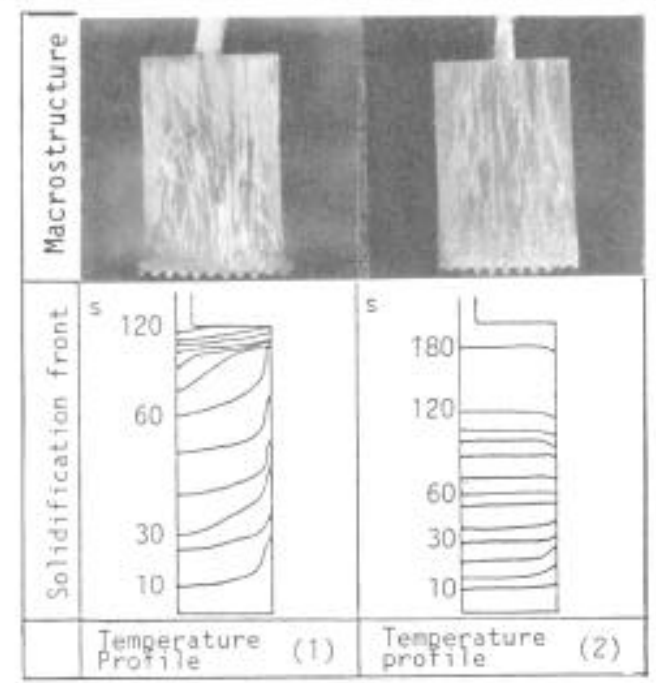

Fig. 6 Solidification front and macrostructure of starter.

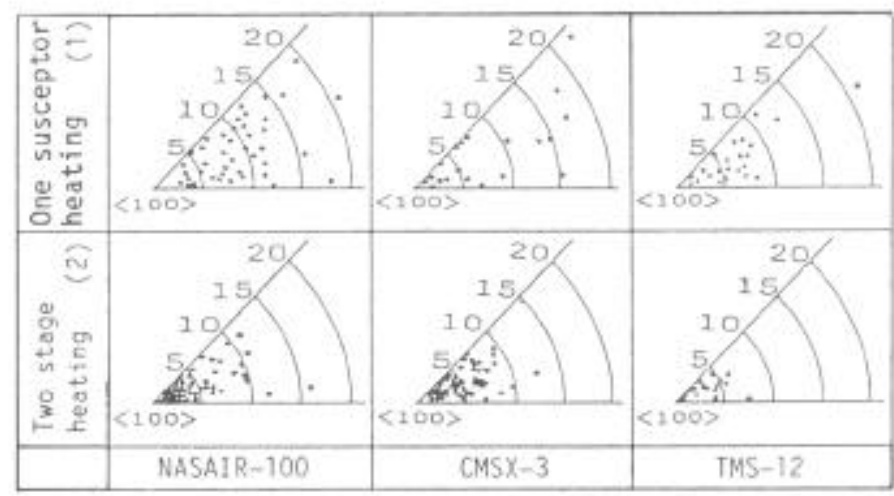

Fig. 7 Distribution of orientation from $\langle 100\rangle$.

As a result of the calculation using temperature profile (2), it was found that the solidification front is horizontal at any position unlike the adoption of temperature profile (1). The columnar crystal of the starter grows upward perpendicularly to the chillplate, which in fact agrees well with the results of the calculation.

Fig. 7 shows the directions of the single crystals cast under mold heating conditions (1) and (2). If it is assumed that single crystals having a deviation of not greater than $10^{\circ}$ from the $\langle 100\rangle$ direction are good products, great improvement in the yield was observed in all alloys used when mold heating condition (2) was adopted. 


\section{1) Two-Stage Heating (Calculation)}

In order to increase the temperature gradient at the solidification front, it is most effective to raise the mold heating temperature. Fig. 8 shows the temperature gradient when the mold heating temperature is raised while making the temperature within the susceptor constant. The temperature gradient becomes higher in proportion to the rise in the mold heating temperature. The rise of the mold heating temperature brings about problems such as: (1) dimensional changes due to deformation of the mold and the core, (2) changes in the composition of the molten metal due to evaporation of the alloying element such as $\mathrm{Cr}$, and (3) reaction of the mold and core with the molten metal. It is, therefore, very useful to increase only the temperature gradient at the solidification front without raising the temperature of the cast as a whole. As one measure, a two-stage heating process in which the temperature of the bottom of the susceptor is raised was investigated.

Fig. 9 shows the change in the temperature gradient at the center of the casting when the temperature of the upper heater is constantly $1500^{\circ} \mathrm{C}$ and the temperature of the lower heater having a height of $70 \mathrm{~mm}$ is varied.

When the temperature of the lower heater is not 1 ower than $1500^{\circ} \mathrm{C}$, the temperature gradient increases in proportion to the temperature of the lower heater, but the increase in the temperature gradient is siightly smaller than that in the case of maintaining the whole susceptor at a uniform higher temperature.

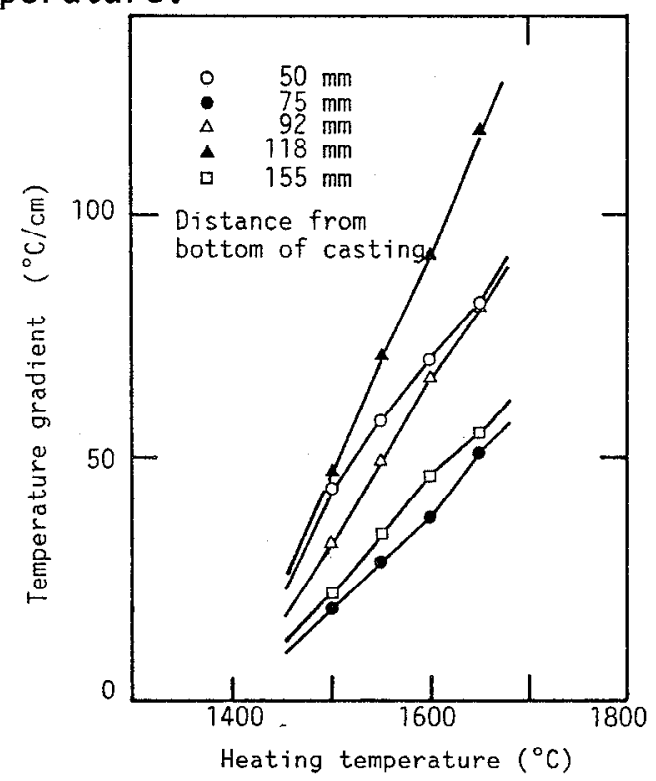

Fig. 8 Effect of heating temperature on the temperature gradient.

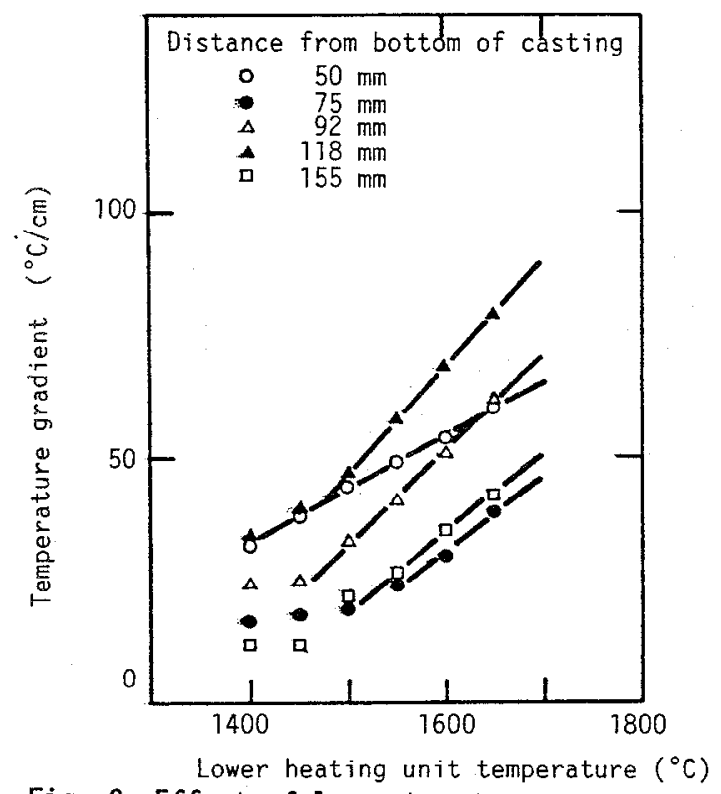

Fig. 9 Effect of lower heating temperature on the temperature gradient. Upper heater $; 1500^{\circ} \mathrm{C}$ Lower heating unit; Height $70 \mathrm{~mm}$

Fig. 10 shows the temperature distribution of the casting when the mold is withdrawn $5 \mathrm{~cm}$ and $10 \mathrm{~cm}$ under the conditions shown in Fig. 9. In proportion to the increase in the temperature of the lower heater, the temperature change in the vicinity of the solidification front becomes large rapidly. However, when the temperature of the lower heater is excessively high, namely $1650^{\circ} \mathrm{C}$, the temperature distribution of the molten metal is reversed.

Fig. 11 shows the rate of increase in gradient in the casting when the temperature of the upper heater is constantly $1500^{\circ} \mathrm{C}$ and the temperature of the lower heater is constantly $1600^{\circ} \mathrm{C}$ while the height of the lower heater is varied. When the height ratio is 0 , the temperature of the whole susceptor is constantly $1500^{\circ} \mathrm{C}$. The larger the height ratio of the lower heater, the larger the temperature gradient obtained. 


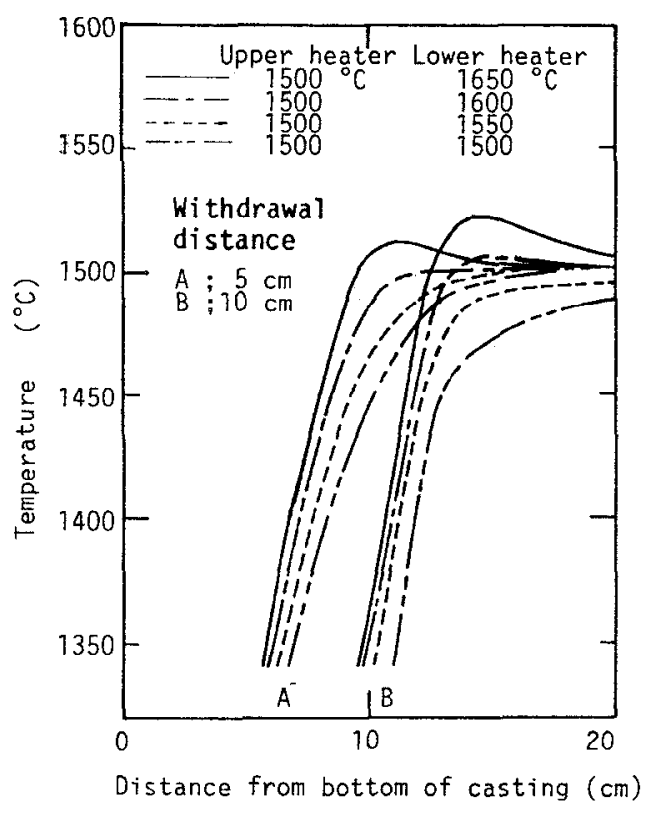

Fig. 10 Temperature profile of casting at several heater temperatures.

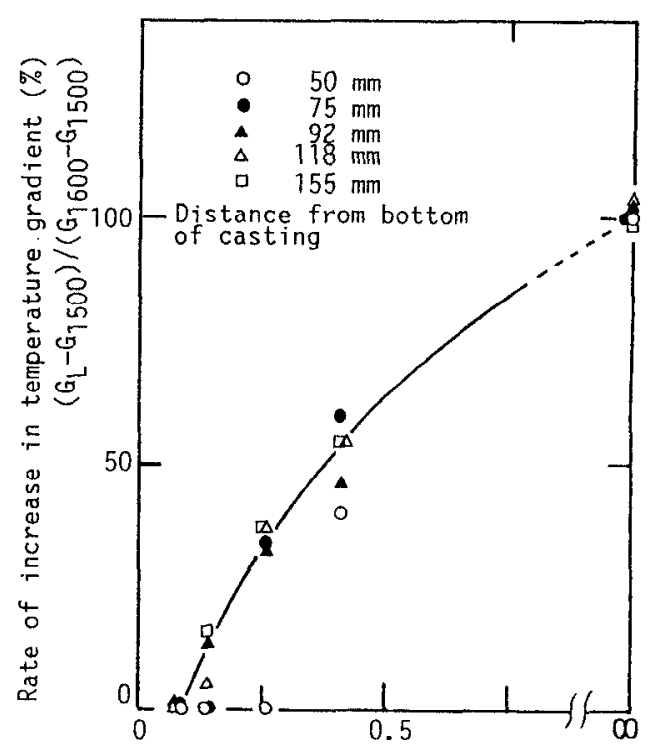

Ratio of heater height (Lower/Upper)

Fig. 11 Rate of increase in temperature gradient vs. heater ratio.

$G_{L}$; Temperature gradient (Lower $=L$ )

G1500: $\quad\left(1500^{\circ} \mathrm{C}\right.$ const. $)$

$\mathrm{G}_{1600 ;} \quad\left(1600^{\circ} \mathrm{C}\right.$ const.)

Fig. 12 shows the change in the temperature gradient with the withdrawal distance of the model airfoil mold under two heating conditions. The temperature gradient is suddenly lowered at the airfoil tip and at the enlarged portion directly above the platform of the casting. However, the change in the temperature gradient is almost the same under both heating conditions.

Fig. 13 shows the temperature distribution in the casting when the mold is withdrawn $5 \mathrm{~cm}, 10 \mathrm{~cm}$, and $15 \mathrm{~cm}$ under the same heating conditions shown in Fig. 12. In spite of having almost the same change in the temperature gradient, a large difference is observed in the temperature distribution in the casting. When the temperature at the bottom of the susceptor is raised by the lower heater, the temperature of the molten metal is $1500^{\circ} \mathrm{C}$ to $1520^{\circ} \mathrm{C}$, while the temperature of the molten metal is as high as $1580^{\circ} \mathrm{C}$ when the whole susceptor is uniformly heated to $1600^{\circ} \mathrm{C}$. Thus, it was found that the two-stage heating process in which the temperature at the bottom of the susceptor is raised is very effective in increasing the temperature gradient solely without raising the temperature of the casting as a whole.

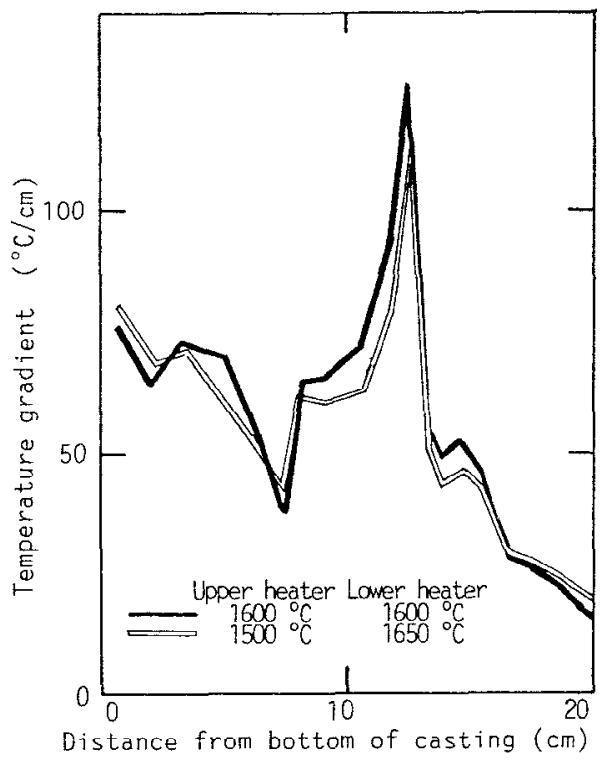

Fig. 12 Temperature gradient of model airfoil at two heating conditions.

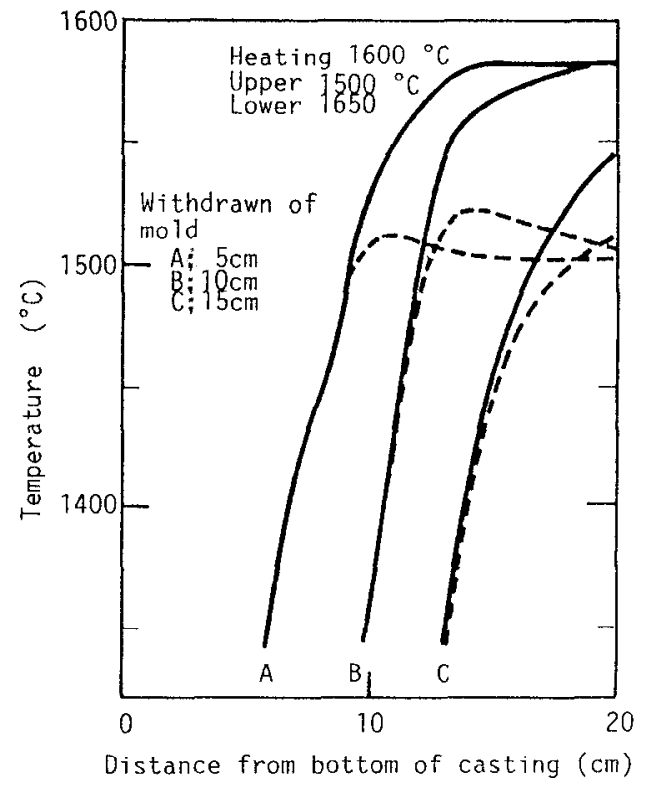

Fig. 13 Temperature profile of casting. 


\section{2) Two-Stage Heating (Experiment)}

Effects of two-stage heating were examined by casting experiments. Two mold heating temperatures were adopted. Fig. 14 shows the temperature distribution in the mold when the mold withdrawal was $0 \mathrm{~cm}, 5 \mathrm{~cm}$, and $10 \mathrm{~cm}$. The slope of the temperature distribution is slightly low in comparison with the results of the calculation, but the effects of the raise at the bottom of the susceptor are still observed.

Fig. 15 shows the change in the temperature gradient obtained from the temperature distribution shown in Fig. 14. The temperature gradient is also increased in proportion to the rise in the temperature at the bottom of the susceptor, which qualitatively agrees with the results of the calculation.

On the basis of these findings, model airfoils were cast from NASAIR100, TMS-12, and TMS-26 alloys. Fig. 16 shows a single crystal model airfoil having a complicated shape. The mold withdrawal rate was constantly $20 \mathrm{~cm} / \mathrm{h}$. Two-stage heating, shown in Fig. 14, was adopted.

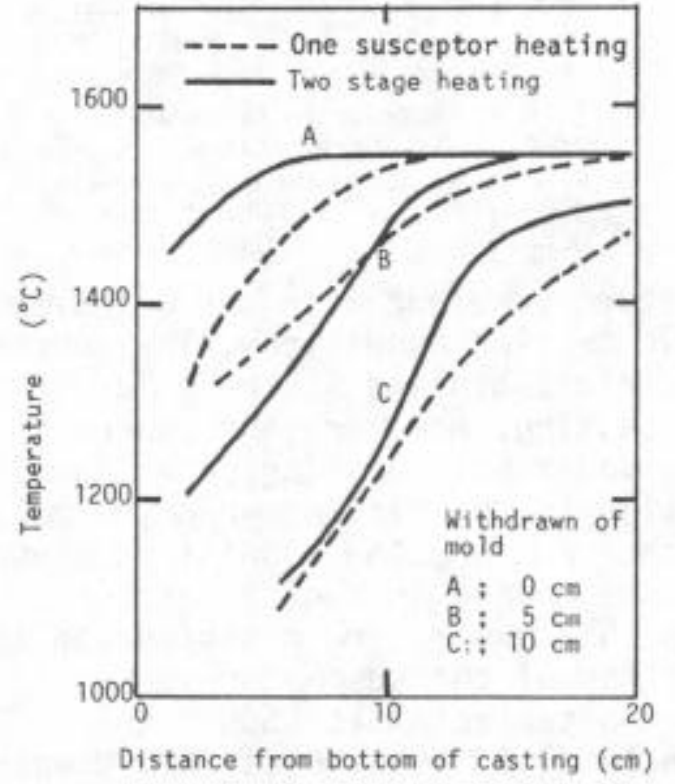

Fig. 14 Temperature profile of mold.

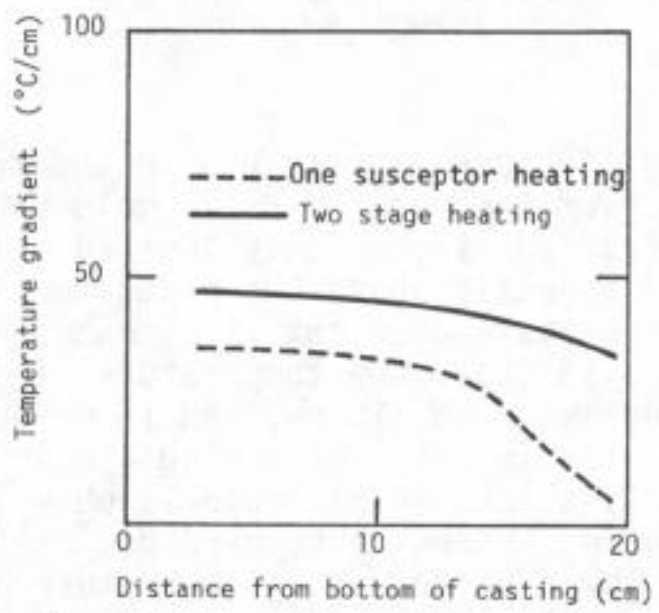

Fig. 15 Change of temperature gradient accompanying withdrawal of casting.

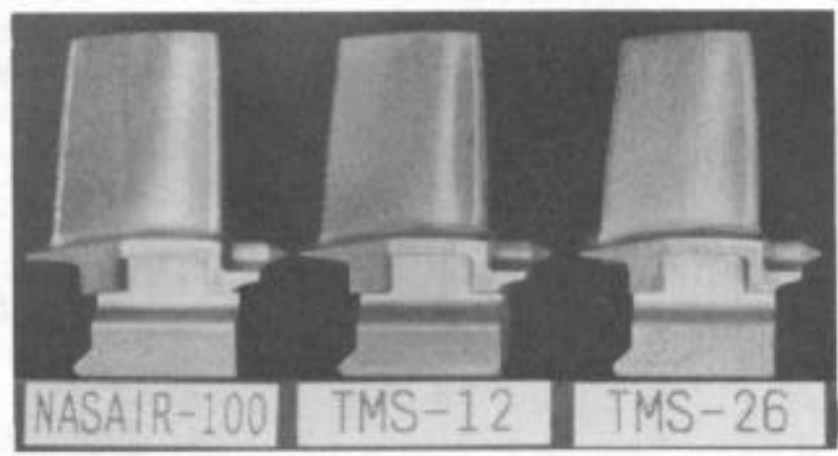

Fig. 16 Single crystal airfoil.

\section{Regulation of Convection}

\section{(Effect of Magnetic Field)}

Fig. 17 shows the external appearance of a single crystal of a Ni-base superalloy obtained while applying a magnetic field during solidification. Conspicuous freckles were produced by the magnetic field. The degree of freckling was different depending on the alloys, with the freckle being more conspicuous in NASAIR-100. Even in the test pieces with freckles, no change was observed in the composition either in the direction of growth or in the 
transverse direction, and no change was observed in the structure of either the vertical section or the cross section due to the magnetic field.

Fig. 18 shows the position at which freckling was produced. Freckling was constantly produced on the left-hand side of the casting relative to the magnetic line of force irrespective of the position in the susceptor and the configuration of the castings.

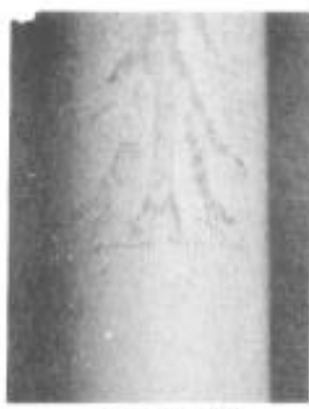

NASATR-100

Fig. 17 Freckle

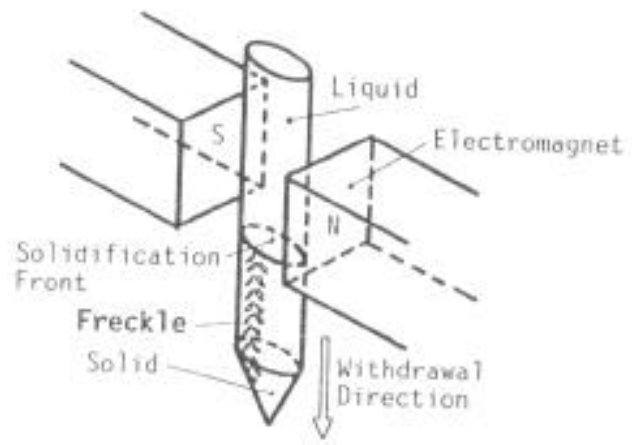

Fig. 18 Generation of freckle.

It is believed that freckling is produced due to the segregation of low-melting point elements (8). However, since freckling in the experiment was produced due to the magnetic field irrespective of the configuration of the casting, it was not caused by the segregation of an element. We consider the cause of freckles to be as follows:

A thermoelectromotive force is generated on the basis of a difference in the molten metal and the mold, the molten metal and the casting, or the mold and the casting, and produces a circuit for a current. When a current flows in this circuit, the magnetic field interferes, so that the molten metal is caused to flow in a constant direction. At the solidification front with which the flow of the current comes into contact, freckles are produced. Since the main constituents of the mold are zircon sand and silica, the mold becomes electrically-conductive in the vicinity of the solidification temperature of the alloy, thereby causing a current to flow on the basis of the thermoelectromotive force.

Clarification of the mechanism for producing freckles including the establishment of the above-described theory remains to be solved in subsequent studies.

\section{Conclusions}

Solidification calculations and casting experiments were carried out for the purpose of improving the accuracy of the direction of growth and increasing the withdrawal speed in a mold withdrawal unidirectional solidification method, and the following conclusions were reached.

1. In order to produce a single crystal of the $\langle 100\rangle$ direction, it is necessary that the starter has a columnar structure.

2. In order to grow a columnar crystal in the starter, it is desirable to raise the pouring temperature and heat the mold above the liquidus of the alloy. If the mold heating temperature is low, the columnar crystal grows obliquely due to the chill from the mold, thereby increasing the difference in the angle between the direction of the vertical axis and the $\langle 100\rangle$ direction of the single crystal.

3. The two-stage heating process in which the temperature at the bottom of the susceptor is raised is very effective for increasing the temperature gradient without raising the casting temperature. 
4. The temperature gradient at the solidification front increases in proportion to the temperature of the lower heater at the bottom of the susceptor. However, when the temperature of the lower heater exceeds a predetermined temperature, the temperature distribution in the molten metal is reversed so that the temperature of the lower portion becomes higher.

5. The effect of raising the temperature at the bottom of the susceptor is manifested when the height of the lower heater is about $10 \%$ that of the upper heater, and the larger the height ratio of the lower heater is, the larger the temperature gradient becomes at the soldification front.

6. In the casting experiments, when the temperature at the bottom of the susceptor was raised, the temperature gradient was increased, which qualitatively agreed with the results of the calculation.

7. Although the application of a magnetic field produced no change in the major components of the alloying elements either in the direction of growth or in the horizontal plane of the castings, freckles which are characteristic of a single crystal casting were produced.

8. The freckles due to the application of the magnetic field were constantiy produced on the left-hand side of the castings relative to the magnetic lines of force irrespective of the configuration of the castings. However, when the mold withdrawal rate was high, the freckles were rarely produced.

9. It is suggested that the freckles were produced by the forced circulation due to the interference of the magnetic field with the thermoelectromotive force which had been produced between the molten metal and the mold, the molten metal and the casting, or the mold and the casting.

\section{Acknowledgement}

This work was performed under management of Research and Development Institute of Metals and Composites for Future Industries as part of the R\&D Project of Basic Technology for Industries sponsored by Agency of Industrial Science and Technology, MITI.

\section{Reference}

1) B.H.Kear, B.J.Piearcey; Trans. Metal.Soc. of A. I.M.E.239('67), 1207

2) F.L.Versnyder, M.E.Shank; Mater.Sci.Eng. 6('70),213

3) J.S.Higginbotham; Mater. Sci.Tech. 2('86), 442

4) R.J.Naumann; J. of Crystal Growth 58(' 82$), 554$

5) H.Kimura, M.F.Harvey, D.J.0'Connor; J. of Crystal Growth 62('83)523

6) G.M.Oreper, J.Szekely; J. of Crystal Growth 67('84) 405

7) S.Morimoto, A. Yoshinari, E.Niyama; Superalloys 84 p177

8) A.F.Giamei,B.H.Kear; Meta11.Trans. 1(' 70), 2185 